Andrea O. Rossetti

\title{
EEG for outcome prediction after cardiac arrest: when the quest for optimization needs standardization
}

Received: 22 April 2015

Accepted: 23 April 2015

Published online: 3 June 2015

(C) Springer-Verlag Berlin Heidelberg and ESICM 2015

\section{A. O. Rossetti (}

Service de Neurologie, BH07, Department of Clinical

Neuroscience, University Hospital (CHUV) and Faculty of Biology and Medicine, 1011 Lausanne, Switzerland

e-mail: andrea.rossetti@chuv.ch

Tel.: +41213141220

Early outcome prognostication of comatose patients following cardiac arrest represents a daunting task; several clinical, biochemical, radiological, and neurophysiological parameters have been intensively evaluated recently, in the context of growing popularity of targeted temperature management or therapeutic hypothermia $(\mathrm{TH})$ in the last decade $[1,2]$. Among these potential predictors, EEG represents a relatively cheap, noninvasive tool available at the bedside, but the assessment of its exact role has to deal with the influence of timing, lingering pharmacological sedation, temperature, and not least the expertise of interpreters and the sometimes confusing taxonomy of the findings.

In this issue, Dr. Sivaraju and colleagues report their effort to assess the prognostic significance of continuous EEG (cEEG) data in 100 patients treated with $\mathrm{TH}$ at $32-34{ }^{\circ} \mathrm{C}$ [3]. They reviewed all EEG recordings in the form of 5-min extracts taken at predefined intervals from the acute event $(6,12,24,48$, and $72 \mathrm{~h})$. Blinded to patients' identity and outcome, they applied the recently published standardized American Clinical Neurophysiology Society
(ACNS) critical care EEG terminology [4], correlating their data with those of other clinical investigations.

The principal findings are that suppression-burst at any time (but not a discontinuous recording), and a low voltage $(<20 \mu \mathrm{V})$ background after $24 \mathrm{~h}$, have a false positive rate of $0 \%$ for poor prognosis, defined as a Glasgow outcome scale (GOS) of 1-3 at hospital discharge, suggesting that in this cohort assessment at $24 \mathrm{~h}$ heralds the best prognostic value, despite the probable concomitant use of sedation (mostly midazolam, further details not given) and TH. As the authors acknowledge, other groups have reported different results regarding the temporal dynamics of evolution of the cEEG [5]; furthermore, the ACNS terminology puts a threshold between suppression-burst and discontinuous background at $50 \%$ of relative suppression, which could prove tricky to label with certainty in specific borderline situations (in other words: EEG signals represent a continuous, not a discrete variable).

Conversely, normal voltage $(>20 \mu \mathrm{V})$ at any time is related to a good outcome in $71 \%$ of patients, confirming earlier data along the same lines [6]. Considering the delicacy in reliably deciding upon a voltage amplitude around $20 \mu \mathrm{V}$ in some patients [7], other groups concentrated rather on background reactivity to stimuli, which if present during $\mathrm{TH}$ has been reported to herald good prognosis in as much as $86 \%$ [8], while lack of reactivity portended a poor prognosis in a much higher rate (99\% in [9]). This last figure contrasts with a predictive value of $86 \%$ in this study (it was, however, not indicated when reactivity was assessed), pinpointing the lack of standardization of its testing (in this series with auditory and peripheral painful stimuli; in the aforementioned papers applying also vigorous pressure to the nipples) and its scoring [7, 10]. In the same context, identical bursts, recently reported to perfectly correlate with poor outcome [11], in this study show an overlapping significance with that of suppression-burst; the 
authors postulate that use of midazolam versus propofol might generate different burst types, and that those induced by propofol might be compatible with good outcome. Again, the difficulties in generalizing the findings are evident.

Coming to clinical prognosticators, lack of corneal reflexes had the lowest false positive prediction of poor outcome $(0 \%)$; the false positive rate regarding occurrence of myoclonus was $14 \%$, especially if a normal voltage was observed, broadly confirming other recent observations [12, 13]; false positivity for the lack motor response was identical, also in line with previous reports [12]. Finally, the authors propose a two-step approach for outcome prognosis, starting with EEG at $24 \mathrm{~h}$ and completing it with corneal reflexes at $72 \mathrm{~h}$.

This is a single-center analysis performed in an environment with the highest expertise for cEEG interpretation, potentially limiting its generalizability; the poor outcome rate of $71 \%$ is higher than that in other recent series [5, 12], but outcome assessment at discharge might have underestimated the recovery of some patients, especially for those in the inhomogeneous category of GOS $($ or $\mathrm{CPC})=3$. Finally, it does not consider biochemical or somatosensory evoked potential (SSEP) variables. Despite the aforementioned limitations, this study is very important, especially for those interpreting EEGs: it shows indeed that the ACNS scoring criteria have a definite place in this clinical setting. Before wide implementation of decisions upon intensive care withdrawal based solely on EEG at $24 \mathrm{~h}$ and corneal reflexes, the present findings definitely need to be validated in a larger cohort, as the authors themselves rightfully conclude. In fact, another recent study showed that inter-rater agreement in a similar clinical context was substantial for suppressed background and burst-suppression, moderate for "benign" EEG features, and fair for reactivity [7], highlighting that real-life EEG scoring of a whole tracing may prove more challenging than scoring selected EEG pages. One practical question somewhat paradoxically arising from this cEEG study relates to its usefulness and cost-effectiveness in postanoxic patients, which has indeed been recently challenged $[14,15]$.

The next step appears to be the consequent integration of the standardized ACNS nomenclature of EEG findings with other predictors [7]. For the time being, a multimodal approach including the maximum available data from different, potentially complementary sources (i.e., clinical, neurophysiologic, biochemical, and radiological) remains mandatory in order to minimize a potentially deleterious effect of the ominous "self-fulfilling prophecy" $[1,2,12]$, which is always somewhat inherent to observational studies in this setting.

Conflicts of interest The author is supported by the Swiss National Science Foundation (CR3213_143780). No conflict of interest applies.

\section{References}

1. Sandroni C, Cariou A, Cavallaro F, Cronberg T, Friberg H, Hoedemaekers C, Horn J, Nolan JP, Rossetti AO, Soar J (2014) Prognostication in comatose survivors of cardiac arrest: an advisory statement from the European

Resuscitation Council and the European Society of Intensive Care Medicine. Intensive Care Med 40(12):1816-1831

2. Nolan JP, Lyon RM, Sasson C, Rossetti AO, Lansky AJ, Fox KA, Meier P (2012) Advances in the hospital management of patients following an out of hospital cardiac arrest. Heart 98(16):1201-1206

3. Sivaraju A, Gilmore EJ, Wira CR, Stevens A, Rampal N, Moeller JJ, Greer DM, Hirsch LJ, Gaspard N (2015) Prognostication of post-cardiac arrest coma: early clinical and electroencephalographic predictors of outcome. Intensive Care Med. doi: 10.1007/s00134-015-3834-x
4. Hirsch LJ, LaRoche SM, Gaspard N, Gerard E, Svoronos A, Herman ST, Mani R, Arif H, Jette N, Minazad Y et al (2013) American Clinical Neurophysiology Society's Standardized Critical Care EEG Terminology: 2012 version. J Clin Neurophysiol 30(1):1-27

5. Cloostermans MC, van Meulen FB, Eertman CJ, Hom HW, van Putten MJ (2012) Continuous electroencephalography monitoring for early prediction of neurological outcome in postanoxic patients after cardiac arrest: a prospective cohort study. Crit Care Med 40(10):2867-2875

6. Rundgren M, Westhall E, Cronberg T, Rosen I, Friberg H (2010) Continuous amplitude-integrated electroencephalogram predicts outcome in hypothermia-treated cardiac arrest patients. Crit Care Med 38(9):1838-1844
7. Westhall E, Rosén I, Rossetti AO, van Rootselaar AF, Kjaer TW, Friberg H, Horn J, Nielsen N, Ullén S, Cronberg T (2015) Interrater variability of EEG intepretation in comatose cardiac arrest patients. Clinical Neurophysiol. doi: 10.1016/j.clinph.2015.03.017

8. Tsetsou S, Oddo M, Rossetti AO (2013) Clinical outcome after a reactive hypothermic EEG following cardiac arrest. Neurocrit Care 19(3):283-286

9. Juan E, Novy J, Suys T, Oddo M, Rossetti AO (2014) Clinical evolution after a non-reactive hypothermic EEG following cardiac arrest. Neurocrit Care. doi:10.1007/s12028-014-0095-4

10. Noirhomme Q, Lehembre R, Lugo Zdel $\mathrm{R}$, Lesenfants D, Luxen A, Laureys S, Oddo M, Rossetti AO (2014) Automated analysis of background EEG and reactivity during therapeutic hypothermia in comatose patients after cardiac arrest. Clin EEG Neurosci 45(1):6-13 
11. Hofmeijer J, Tjepkema-Cloostermans MC, van Putten MJ (2014) Burstsuppression with identical bursts: a distinct EEG pattern with poor outcome in postanoxic coma. Clin Neurophysiol 125(5):947-954

12. Oddo M, Rossetti AO (2014) Early multimodal outcome prediction after cardiac arrest in patients treated with hypothermia. Crit Care Med 42(6):1340-1347
13. Seder DB, Sunde K, Rubertsson S, Mooney M, Stammet P, Riker RR, Kern $\mathrm{KB}$, Unger B, Cronberg T, Dziodzio J et al (2015) Neurologic outcomes and postresuscitation care of patients with myoclonus following cardiac arrest. Crit Care Med 43(5):965-972
14. Alvarez V, Sierra-Marcos A, Oddo M, Rossetti AO (2013) Yield of intermittent versus continuous EEG in comatose survivors of cardiac arrest treated with hypothermia. Crit Care 17(5):R190

15. Crepeau AZ, Fugate JE, Mandrekar J, White RD, Wijdicks EF, Rabinstein AA, Britton JW (2014) Value analysis of continuous EEG in patients during therapeutic hypothermia after cardiac arrest. Resuscitation 85(6):785-789 